\title{
A qualitative study of the communication and information needs of people with learning disabilities and epilepsy with physicians, nurses and carers
}

\author{
Jerry Paul K. Ninnoni®
}

\begin{abstract}
Background: Living with a chronic condition such as epilepsy can have a debilitating effect on the individual and their carers. Managing epilepsy among people with learning disabilities may present a challenge because of limited communication and may require a multidisciplinary approach. The study investigated the communication and information needs of people with learning disabilities with epilepsy and their physicians, nurses and carers.

Methods: Qualitative designed was adopted to collect data from 15 community-based people with mild learning disabilities with epilepsy and 13 carers. Recorded data were transcribed verbatim and analysed thematically.

Results: A range of findings emerged related to patient communication and information needs. These included: Knowledge regarding epilepsy; involvement; honesty and openness when giving information and consistency in provision of information.

Conclusion: People with learning disabilities with epilepsy and their carers would like to know more about epilepsy, to be more involved decision makings through communication in the management of epilepsy to enable them feedback information regarding their health.
\end{abstract}

Keywords: Learning disabilities, Epilepsy, Communication, Carers, Physicians, Nurses

\section{Background}

Effective communication is more than just providing information but transactional between the communication partners. It involves understanding the emotion and reasons behind the information. In addition to being able to convey a message, there is a need to listen in a way that gains the full meaning of what is being communicated and the other party feels being heard and their views considered. Thus, effective communication is central to the management of service users who have learning disabilities with epilepsy and their doctors, nurses and carers.

Seizure control maybe one of the main goals for medical and nursing staff as well as for people with learning disabilities and their carers [1]. The individual with epilepsy will need to have knowledge of the condition and

Correspondence: jerry.ninnoni@ucc.edu.gh

School of Nursing and Midwifery, Department of Mental Health, University of Cape Coast, Cape Coast, Ghana be able to communicate information regarding seizures, medications and side effects $[2,3]$. It is claimed that people with learning disabilities are at greater risks of seizures compared with the epilepsy population overall [4-6] and mortality is increased among the learning disabilities population [7]. Also, people with epilepsy who live in institutional settings have better seizure control when compared with those in community settings [813 ] and this may reflect the availability of specialist services in residential settings. Following deinstitutionalisation, there are increased numbers of people with learning disabilities and epilepsy residing in communities either living independently or supported by carers who may have limited knowledge and information regarding epilepsy [14, 15]. However, patients and carers' knowledge and information regarding epilepsy may facilitate communication with health professionals such as doctors and nurses. 
Non-adherence may imply a refusal to seek healthcare, non-participation in health management or failure to follow doctors' instructions [16, 17]. It may also take other forms for example, the information or education given by healthcare professionals is either misunderstood, administered wrongly or the information is ignored completely $[18,19]$. All these could be due to a range of factors including communication lapses and inadequate information provision [20,21]. The philosophy of concordance advocates a decision-making process where patients can feel more involved in communication and more comfortable with their treatment [22]. It is argued that adherence is a multivariate construct that is determined by the interplay of many factors [14, 20]. Aspects may reflect the complexities of treatment regimes, level of support and the individuals living circumstances $[14,23]$. A study by Eastock and Baker [24] reported that failure to comply with treatment is common among people with epilepsy compared with other chronic conditions. And the reasons for non-adherence included; lack of understanding of why it was necessary to adhere to treatment and the level of information provision, doctor-patient relationship, psychosocial factors and patient characteristics $[24,25]$. It has also been found that patients reporting with side-effects are more likely to be non-adherent [20,25]. This may be due to poor communication and are reported higher among individuals with learning disabilities who are also more susceptibility to unidentified side effects [20, 26, 27].

Partnership has been identified as a key determinant of patient satisfaction and the involvement of the patient in decision-making is important to promoting adherence [28]. Studies have shown that patient satisfaction and adherence are ultimately linked to patient involvement in the treatment $[18,29]$. Patients who feel their healthcare professionals communicate well with them and actively encourage them in their own care are more likely to adhere to treatment [30-33]. Service providers are required to develop a reciprocal relationship where the exchange of information, identification of problems and the development of solutions are shared with the patient where they can input in the communication exchanges $[34,35]$. It is asserted that when patients see themselves as partners and as problem solvers it may motivate them to exchange information more freely and they are more likely to adhere to their treatment recommendations [34, 36]. Yet, it is unclear to what extent service users with learning disabilities and epilepsy are involved in communication regarding services provision. Also, people with learning disabilities are more likely to acquiesce during conversations [37, 38]. Therefore, there is a need to encourage and support people with learning disabilities to express their views and feelings [39-43]. Community-based people with learning disabilities and epilepsy may want to lead an independent life and adopt a more consumerist perspective regarding the services they receive and thus there is a need for effective communication.

However, little is known regarding the views of people with learning disabilities with epilepsy and carers communication with doctor and nurses. There is a paucity of research that investigated people with learning disabilities and epilepsy views regarding communication [44]. To a larger extent, communication studies regarding people with learning disabilities are more common among children populations [45-47], are based on institutional or residential settings and included people with severe to profound learning disabilities [48, 49]. However, community-based adults with learning disabilities and epilepsy may have different communication needs and expectations. In addition, studies involving people with learning disabilities are mostly one-sided regarding the individuals' perspectives of communication. The individuals with learning disabilities views regarding communication are often not reported. Studies focused predominantly on staff views and developing their communication skills to the neglect of service user's regarding communication. Thus, an important aspect is missing as communication is at least a two-way process. Besides, little is known regarding people with learning disabilities with epilepsy views and experiences regarding communication with doctors, nurses and carers. The study sought to bridge this gap by giving a voice to people with learning disabilities and epilepsy to express their views regarding communication with doctors and nurses.

\section{Methods}

This study utilised a descriptive qualitative approach using face-face interviews to explore the views and experiences of people with learning disabilities and epilepsy and their carers regarding communication with physicians and nurses.

\section{Setting}

The study was conducted in a rural area in the North of Scotland as part of The Managed Clinical Network for Epilepsy which comprises the Community Learning Disability Teams, Epilepsy Field-workers, Neurologists, General Practitioners and Consultants.

\section{Population and sampling procedure}

Purposive sampling techniques were used to identify the people with epilepsy and learning disabilities who met the inclusion criteria. Participants were recruited through the learning disabilities teams who identified the participants within the locality. Inclusion criteria were adults with mild learning disabilities with confirmed diagnosis of epilepsy; receiving learning disabilities services as identified by the 
consultants and aged $16-50$ years. Only people who gave written informed consent were sampled.

\section{Ethical approval}

The study was approved by the Grampian Research Ethics Committee.

\section{Data collection}

Data were collected using semi-structured interviews. Data saturation was reached with 15 services users and 13 carers. Each interview lasted about 30-40 min. Interviews were taped with the participant consent. Participants were interviewed either at the Surgery, Day centre or at home as deemed convenient by the participant. Two carers were excluded from the study (one care-worker did not meet the inclusion criteria and the other declined to participate in the study). All participants except two carers consented to the interviews to be taped. The researcher was permitted to keep written notes of the non-recorded interviews. Interview questions were largely about communication exchanges and information provision between services users, doctors, nurses and carers regarding epilepsy. Specific questions were on patients and carers' information needs regarding epilepsy.

\section{Data analysis}

Thematic data analysis approach [50] was adopted. Data were transcribed verbatim. Transcripts of about 50 pages were printed. The transcripts were read through several times to obtain a sense of the whole [51]. Participants experiences of communication and information provision with healthcare professionals and carers regarding epilepsy and related issues constituted the unit of analysis. Each interview was read, and margins and notes made to form initial codes [52]. The interview was divided into meaning units that were condensed such as communication exchanges, information provision, involvement, listening and understanding. Significant statements and commonalties were organised into themes representing clearly define response category [50]. Emergent themes were documented and discussed to ensure inter-rater reliability. In the event of disagreements regarding themes the transcripts were revisited and analysed until consensus was reached. Identified themes were matched with the initial category.

\section{Participants characteristics}

Two carers had learning disabilities but not epilepsy and one carer also had epilepsy but not a learning disability. In terms of demographic characteristics $61 \%$ of the participants were females [22] and 39\% [12] males (Tables 1 and 2 respectively).

Overall, the nature of seizure control in most of the patients was reported as good by patients and carers.
Table 1 Characteristics of patients

\begin{tabular}{llll}
\hline Patients (Codes) & Gender & Place of interviews & Relationship with carer \\
\hline PA & F & Daycentre & Patient/daughter \\
PC & F & Daycentre & Patient \\
PE & M & Home & Patient/husband \\
PG & M & GP Surgery & Patient \\
PI & M & Home & Patient \\
PK & F & Home & Patient \\
PM & M & Home & Patient \\
PN & F & Home & Patient \\
PP & M & Home & Patient \\
PR & F & Home & Patient/wife \\
PT & F & Home & Patient \\
PV & F & Home & Patient \\
PX & F & Home & Patient \\
PY & M & Home & Patient/husband \\
PAa & F & Home & Patient \\
\hline
\end{tabular}

However, in a few participants, the epilepsy control was reported as poor. Participants were given the choice to decide the location for the interview for example, at their own home, day centre, a GP surgery or at the university. The majority 79\% [21] preferred and were interviewed at home and the others $21 \%$ [7] at either the GP Surgery or Day-care centres (Tables 1 and 2). Regarding patient/carer relationships, 11 were care-workers with only four family carers. The types of support provided for patients was mainly based on activities of daily living with very little or no involvement in health managements.

Table 2 Characteristics of carers/care-workers

\begin{tabular}{llll}
\hline Carer code & Gender & Interview location & Relationship with patient/s \\
\hline PB & F & Daycentre & Family carer \\
PD & M & Daycentre & Care-worker \\
PF & F & Home & Family carer \\
PH & M & GP Surgery & Care-worker \\
PJ & F & Patient home & Care-worker \\
PL & M & Patient home & Care-worker \\
PO & F & Patient home & Care-worker \\
PQ & F & Patient home & Care-worker \\
PS & M & Patient home & Family carer \\
PU & M & Patient home & Care worker \\
PW & F & Patient home & Care worker \\
PZ & F & Patient home & Family carer \\
PAb & F & Patient home & Care worker \\
\hline
\end{tabular}




\section{Results}

The study yielded a range of concerns relating to patients (service users) and carers' communications needs with doctors and nurses. Concerns expressed by both service users and carers related to knowledge and the inadequacy of information provision by doctors and nurses. However, this appeared to vary among different professional groups. Service users reported they would like to be more involved in decision making regarding their care. They wanted interactions and relationship with doctors and nurses built on trust and information provision to be consistently shared. Four main themes characterised patients and carers' communication and information need with doctors and nurses.

\section{Theme 1. Knowledge regarding epilepsy}

Service users and carers expressed the desire to communicate effectively but appeared to be constrained by their limited knowledge regarding epilepsy, seizures and medication. They both expressed the need to know more about epilepsy and would value some form of training to improve their knowledge on epilepsy and seizures:

'...... a gap in knowledge because I don't know obviously enough about as much as I should because I work with her and more knowledge for what to look out for, just general knowledge of epilepsy would be ideal' Care worker PAb

'I understand there are training programmes, but I have not been yet' Care worker PAb

'She [carer] would like to know more about it as I would like. That is what she needs to do, to learn something about epileptic fits' Patient PE

'I asked, and I was given a DVD video for a shot and return it but it does not teach me anything. I would like to know more about epilepsy of what to do if he takes a 'turn' [seizures]. What I need is somebody to come up and sit down with me and tell me more about epilepsy is all I need but everybody is busy and I am not the pushy type of person' Family carer PF

\section{Theme 2. Involvement}

Overall, service users and carers' communication purpose and needs with doctors and nurses were based on a wide range of things. However, involvement in decision making was central to their communication needs, they want to be more involved in communication. Service users have consistently expressed concerns regarding their lack of involvement in communication although this appears to vary among doctors and nurses:

'The doctors will tell you, take your tablets and that is it, whereas people like [nurse] will help you, talk to you about it, sit down face-to-face whereas doctors will want you out of the door' Patient PP

Similarly, carers expressed their wishes to be more involved in decision-making regarding patients and to be able to advocate for patients when necessary but felt they have often been side-lined by the doctors when making decisions for service users.

'I would just like to be able to talk a lot more about her so that if I am worried, I can discuss it with them and between us we can put it right hopefully' Family carer $P B$

'........I tried to change her appointment because she had no time to do it or something and I phoned the reception and say could she change it from this time to that and they said they are sorry they could not do it because it was confidential and that was just stupid because it has nothing to do with medicine. She was just asking to change but I suppose maybe they do get some 'nutters' who would do it for fun but I am her mum. Is stupid because they knew I am her mum they can identify the two of us together. I think if you know the way she is they should be a bit more forthcoming because she can't always relay it to me you know' Family carer $P B$

\section{Theme 3. Honesty and openness in the provision of information}

Other concerns that were repeatedly expressed by service users were related to the issue of withholding or concealing information. Service users wanted more discussions regarding changes to medications to be openly and honestly discussed with them. It appears there is conflict between autonomy and paternalism as reported:

'I find it very difficult sometimes you have a very bad back problem. I used to get pain killers for bad back ache, but they have taken them out these pills that I used to, they don't have any side effects with my medications but they have taken them off' Patient PT

'There was one doctor I think last week I have been on medication for my depression and one doctor tries to 
reduce it because I have not been getting the truth that $o k$... [doctors] have reduced it and all that my antidepressant but on Friday I have to go past and get it put back to normal' Patient PC

\section{Theme 4. Consistency in the provision of information} Furthermore, other concerns related to conflicting information from doctors and nurses and the need for consistency in the provision of information. Service users and carers would value consistency in making decision where both carers and services are aware of decisions that are taken:

'They have put a stop to my other tablets that I used to take but I don't know why, I think the... [nurse] said the learning disabilities team agreed on that but when I spoke with my Mum, my Mum said I was best taking two at lunch time instead of the one' Patient PT

This view was also shared by carers' who advocated for their involvements in multidisciplinary team meetings to ensure that information is consistently shared:

'There is a stumbling block because is happening right now, she is coming to me with her problems but she not sharing the same problems with her GP, she not sharing the same problem with the Psychiatric nurse, but I feel uncomfortable going to the GP because I will be crossing boundaries here and I rely on her to convey appropriate information' Care worker PD

'But sometimes I just wish that there was a bit more communication with the support workers from the doctors and nurses but then everybody is busy' Care worker $P Q$

Persistent concerns expressed by both service users and carers related to lack of trust. Service users expressed concerns regarding medication errors. This led to patients questioning whether they were getting the prescribed or wrong medication. This was reported to be affecting their trusting relationships with doctors and nurses:

'Medication is funny, there are so many things going on with my medication. For instance, the doctors got mixed up between my medication and my brother's medications, how is that? I try to understand whether I take different, medications' Patient PP

'I have been to the hospital here for once I don't know when, when I was four years, but they did not give me the right medicine. This is what I cannot understand they have all your notes there and everything but give you the wrong medicine sometimes' Patient PM

This view regarding errors in medication was corroborated by the carer's own observation of the error in the medication:

'He [patient] asked me a few months ago to double check his tablets because he felt the tablets were wrong and I did, and the tablets were definitely wrong and we both went down to the doctors to get everything sorted out' Care worker PQ

Service users also reported that they are not being trusted by doctors especially when reporting their experiences with medications and side effects:

I am finding that I am sweating a lot because of the dizziness, I get angry because trying to explain to the doctors, sometimes when you are telling them you wonder if they believe you, it makes me cross sometimes. But is actually, you are going through it and they are just sitting on the chair and you wonder if they are taking it all in' Patient PP

\section{Discussion}

The study explored service users' and carers' views and experiences of communication with doctors and nurses. The findings of this study demonstrated the complexities of communication involving people with learning disabilities and epilepsy. The findings indicated that service users have numerous communications need with their doctors, nurses and carers which appears to be impacting on quality of life.

\section{Epilepsy knowledge and information}

It emerged from the study that both service users and carers considered knowledge regarding epilepsy and medication as a significant tool that may enhance communication, but this appears to be limited and evident by carers' lack of knowledge regarding epilepsy and seizures. Carers need for knowledge and information regarding epilepsy concurs with earlier studies in the general population [15] but has not been reported by people with learning disabilities and epilepsy. Kendall and colleagues [53] also reported similar findings in their study, within an epilepsy organisation, regarding carers' information needs relating to medications and side effects. The Scottish Intercollegiate Guidelines Network (SIGN) guidelines for epilepsy recommend that adults and their carers have the right to accurate information about the condition including the 
specific epilepsy syndrome, its treatment and implications for everyday life $[54,55]$.

\section{Service users and carers involvement}

Lack of involvement in issues relating to epilepsy with doctors and nurses was reported as a concern by service users. The study demonstrated that service users appear to value more egalitarian relationships with doctors and nurses and would like to input on issues regarding their health [38]. It is claimed that most healthcare policies fit under the banner of patient and public involvement where interactions between patients and health professionals are encouraged [56]. Therefore, improving communication between patients and professionals and a shift away from paternalism to a more patient-focused approach has the potential to improve patient care [56]. People with learning disabilities in the community may have different communication and support needs compared with institutional settings and may want to be more involved in decision making that reflect their living conditions. This was reflected in the current study however a follow up study with doctors may present a full picture of this finding.

\section{Trust and credibility}

Service users reported a need for information to be honestly and openly discussed with them. However, they perceived the information they get from doctors and nurses as insufficient and often they contribute little to the discussions. This however, was reported to vary among doctors and nurses. It is argued that whilst health professionals may be primarily interested in symptom reduction [57], service users in this study want to have an open discussion with their health care professionals regarding the management of their conditions where they can input regarding their health. The findings also point to the perceived lack of honesty between service users and doctors and nurses [58, 59]. This related to the apparent concealing and withholding of information from service users. It is claimed that health professionals commonly withhold health information from patients with their tacit consent $[60,61]$. It is further argued that withholding information from patients may be ethically permissible and more generally, that honesty is not always the best policy [61]. However, in contemporary health care practice, patients are increasingly expected not only to know their diagnosis but also have detailed information regarding treatment options and prognosis $[60,61]$. Service users highlighted a lack of trust and credibility when communicating with doctors relating to medication and side effects. A service user reported a lack of trust with the doctors as negatively impacting on communication. Patients expressed concerns regarding the medication they receive, fearing that they may be receiving the wrong medication: The prevalence of medication errors had been reported in the general population $[62,63]$. It is claimed that medication prescribing deficiencies are the most common cause of actual and potential adverse drug events [64-66].

Furthermore, service users have concerns relating to lack of trust with doctors especially regarding medication side effects. They reported that doctors do not appear to believe them when reporting side effects. This finding reflect previous studies in the general population which revealed misunderstanding and disagreements regarding medication side effects [19]. To a significant extent, doctor-patient relationship is dependent on trust; and effective communication is nurtured in trusting relationships [67, 68]. All health professional bodies, for example, the General Medical Council and the Nursing and Midwifery Council both emphasize the need to maintain trust with patients as a top priority. People with learning disabilities and epilepsy are more likely to be taking multiple medication and may be particularly susceptible to antiepileptic drug side effects [69-71].

The significance of trust between patients and health care professionals has been widely reported in the literature [72-74]. Trust is said to be vital to patient-doctor relationships and with other health care professionals and can mediate important behaviours and health outcomes $[74,75]$. Patients perceive more trust in health care professionals who use more patient-centred in communication [74]. Other studies reported trust to be positively associated with the doctors' experiences and also to be dependent on the patient-doctor relationships [73].

\section{Information sharing}

This study showed that both service users and carers' communication with doctors and nurses also related to the need to share information consistently regarding epilepsy. People with learning disabilities and epilepsy may have different communication needs that require multidisciplinary team approach and they need to have information consistently shared with carers, doctor and nurses. Providing accurate and consistent information about epilepsy and seizure managements are core tenets of patient-centred care [76, 77]. The importance of multidisciplinary approach to addressing the communication needs of adults with learning disabilities have been captured in the literature [78]. A similar study also reported that patients are confused by the conflicting advice from doctors and nurses [19]. It can be argued that people with learning disabilities are particularly vulnerable to medication errors due to possible communication difficulties and cognitive impairments. Therefore, consistent information sharing with nurses and carers in medication management may be crucially important. 


\section{Limitations of the study}

This is a qualitative study in a small geographical location in Scotland and thus no attempts are made to generalise the findings to a wider context. Also, study only focused on the views of service users and their carers but not doctors and nurses.

\section{Conclusions}

Service users and carers communication experiences with doctors and nurses include: limited knowledge of epilepsy involvement in decision-making; maintaining trusting relationships with doctors and nurses and a multidisciplinary approach to health management involving carers to ensure information is comprehensive and consistently shared.

The findings reveal gaps in communication between doctors, nurses and carers. These may have implication for practice regarding the role of effective communication to improving epilepsy care among this population group. Also, doctors and nurses may need to adopt the domains of patient-centred models where the patients are more involved, and their views and beliefs respected in the encounter. The findings also implied healthcare professionals may need to reflect, adjust and adopt a more patient-centred approach when engaging with patients. Also, the findings suggest that policies focusing on the involvement of people learning disabilities are translated in clinical practice. The findings also have implications on education. Professional practice. Public awareness and health literacy must be increased, beginning with education of students' nurses and other health professionals to improved doctor-patient communication skills.

\section{Abbreviations}

PCC: Patient-Centred Care; SIGN: Scottish Intercollegiate Guidelines Network

\section{Acknowledgements}

The following people and organisations deserved acknowledgement

1. Dr. Anita F Young, Robert Gordon University, UK

2. Professor Sylvia Mupepi, Grand Valley State University, USA

3. North of Scotland Managed Clinical Network for Epilepsy, Aberdeen Scotland.

4. Robert Gordon University

\section{Funding}

The study was funded by the Health Services Research Group, School of Nursing and Midwifery, Robert Gordon University, UK.

\section{Availability of data and materials}

Data collected from this study were archived in accordance with the Robert Gordon University policy and as required by the Grampian Research Ethics Committee. However, data can be made available by corresponding author on request.

\section{Author's contributions}

JPKN: Contributed to the literature review, study design, data collection, analysis and interpretation, discussions, drafting the manuscript and critically revising.

\section{Ethics approval and consent to participate}

The study was approved by the Grampian Research Ethics Committee, Aberdeen, Written consent was sought from all participants regarding voluntary participation.

\section{Consent for publication}

Not applicable in this study.

\section{Competing interests}

The author declares that he/she has no competing interests.

\section{Publisher's Note}

Springer Nature remains neutral with regard to jurisdictional claims in published maps and institutional affiliations.

Received: 20 March 2018 Accepted: 26 December 2018

Published online: 19 January 2019

\section{References}

1. Sander JW. The natural history of epilepsy in the era of new antiepileptic drugs and surgical treatment. Epilepsia. 2003;44(Suppl 1):17-20.

2. Kerr M. Clinical guidelines for the management of epilepsy in adults with an intellectual disability. Seizure. 2001;10:401-9.

3. Kerr M, Bowley C. Evidence-based prescribing in adults with learning disability and epilepsy. Epilepsia. 2001;42(Suppl 1):44.

4. Scheepers B, Salahudeen S, Morelli J. Two-year outcome audit in an adult learning disability population with refractory epilepsy. Seizure. 2004;13(8): 529-33.

5. Moran NF, Poole K, Bell G, Solomon J, Kendall S, McCarthy M, et al. Epilepsy in the United Kingdom: seizure frequency and severity, anti-epileptic drug utilization and impact on life in 1652 people with epilepsy. Seizure. 2004; 13(6):425-33.

6. Espie CA, Watkins J, Duncan R, Sterrick M, McDonach E, Espie E, et al. Perspectives on epilepsy in people with intellectual disabilities: comparison of family carer, staff carer and clinician score profiles on the Glasgow Epilepsy Outcome Scale (GEOS). Seizure. 2003;12(4 (Print)):195-202.

7. Robertson J, Hatton C, Emerson E, Baines S. Mortality in people with intellectual disabilities and epilepsy: a systematic review. Seizure. 2015;29: 123-33.

8. Branford D, Bhaumik S, Duncan F. Epilepsy in adults with learning disabilities. Seizure. 1998;7(6):473-7.

9. Branford D, Bhaumik S, Duncan F, Collacott RA. A follow-up study of adults with learning disabilities and epilepsy. Seizure. 1998;7(6):469-72.

10. Huber B, Hauser I, Horstmann V, Jokeit G, Liem S, Meinert T, et al. Seizure freedom with different therapeutic regimens in intellectually disabled epileptic patients. Seizure. 2005;14(6):381-6.

11. Huber B, Seidel M. Update on treatment of epilepsy in people with intellectual disabilities. Curr Opin Psychiatry. 2006;19(5):492-6.

12. Huber B, Hauser I, Horstmann V, Jokeit G, Liem S, May T, et al. Long-term course of epilepsy in a large cohort of intellectually disabled patients. Seizure. 2007;16(1):35-42.

13. Sander JW. Epilepsy; epidemiology. In: Aminoff MJ, Daroff RB, editors. Encyclopedia of the neurological sciences (Second Edition). Oxford: Academic Press; 2014. p. 108-11.

14. Rasaratnam R, Crouch K, Regan A. Attitude to medication of parents/ primary carers of people with intellectual disability. J Intellect Disabil Res. 2004:48:754-63.

15. McEwan L, Taylor J, Casswell M, Entwistle R, Jacoby K, Gorry J, et al. Knowledge of and attitudes expressed toward epilepsy by carers of people with epilepsy: a UK perspective. Epilepsy Behav. 2007;11(1):13-9.

16. Cramer JA, Roy A, Burrell A, Fairchild CJ, Fuldeore MJ, Ollendorf DA, et al. Medication compliance and persistence: terminology and definitions. Value Health. 2008:11(1):44-7.

17. Vermeire $E$, Hearnshaw $H$, Van Royen P, Denekens J. Patient adherence to treatment: three decades of research. A comprehensive review. J Clin Pharm Ther. 2001;26(5):331-42.

18. Martin LR, William SL, Haskard KB, DiMatteo RM. The challenge of patient adherence. Ther Clin Risk Manag. 2005;1(3):189-99.

19. Britten N, Stevenson FA, Barry CA, Barber N, Bradley C. Misunderstandings in prescribing decisions in general practice: qualitative study. Br Med J. 2000; 320:484-8. 
20. Loiselle K, Rausch JR, Modi AC. Behavioral predictors of medication adherence trajectories among youth with newly diagnosed epilepsy. Epilepsy Behav. 2015;50:103-7.

21. Gabr WM, Shams MEE. Adherence to medication among outpatient adolescents with epilepsy. Saudi Pharm J. 2015;23(1):33-40.

22. Marinker M, Shaw J. Not to be taken as directed: putting concordance for taking medicines into practice. BMJ. 2003;326(7385):348-9.

23. Perkins $\mathrm{R}$. What constitutes success? The relative priority of service users' and clinicians' views of mental health services. Br J Psychiatry. 2001;179:9-10.

24. Eatock J, Baker GA. Managing patient adherence and quality of life in epilepsy. Neuropsychiatr Dis Treat. 2007;3(1):117-31.

25. Buck D, Jacoby A, Baker GA, Chadwick DW. Factors influencing compliance with antiepileptic drug regimes. Seizure. 1997;6(2):87-93.

26. Hannah JA, Brodie MJ. Epilepsy and learning disabilities--a challenge for the next millennium? Seizure. 1998;7(1 (Print)):3-13.

27. Wilcox J, Kerr M. Epilepsy in people with learning disabilities. Psychiatr Learn Disabil. 2006:5(10):372-7.

28. Winefield HR, Murrell TG, Clifford J. Process and outcomes in general practice consultations: problems in defining high quality care. Soc Sci Med. 1995;41(7):969-75.

29. Poole K, Moran N, Bell G, Solomon J, Kendall S, McCarthy M, et al. Patients' perspectives on services for epilepsy: a survey of patient satisfaction, preferences and information provision in 2394 people with epilepsy. Seizure. 2000;9(8):551-8.

30. Pelzang R. Time to learn: understanding patient-centred care. Br J Nurs. 2010;19(14):912-7.

31. Redman RW, Lynn MR. Advancing patient-Centred care through knowledge development. CJNR (Canadian Journal of Nursing Research). 2004:36(3):116-29.

32. Epstein RM, Franks P, Fiscella K, Shields CG, Meldrum SC, Kravitz RL, et al. Measuring patient-centered communication in patient-physician consultations: theoretical and practical issues. Soc Sci Med. 2005;61(7):1516-28.

33. Buelow J, Johnson J. Self-Management of Epilepsy: a review of the concept and its outcomes. Dis Manag Health Outcome. 2000:8(6):327-36.

34. Young A, Flower L. Patients as partners, patients as problem-solvers. Health Commun. 2002;14(1):69-97.

35. Prinjha S, Chapple A, Herxheimer A, McPherson A. Many people with epilepsy want to know more: a qualitative study. Fam Pract. 2005;22(4):435-41.

36. Mead N, Bower P. Patient-centred consultations and outcomes in primary care: a review of the literature. Patient Educ Couns. 2002:48(1):51-61.

37. Grove N, Bunning K, Porter J, Olsson C. See what I mean: interpreting the meaning of communication by people with severe and profound intellectual disabilities. J Appl Res Intellect Disabil. 1999;12(3):190-203.

38. Rodgers J, Namaganda S. Making information easier for people with learning disabilities. Br J Learn Disabil. 2005;33(2):52-8.

39. O'Gara PE, Fairhurst W. Therapeutic communication part 2: strategies that can enhance the quality of the emergency care consultation. Accid Emerg Nurs. 2004;12(4):201-7.

40. Hironaka LK, Paasche-Orlow MK. The implications of health literacy on patient-provider communication. Arc Dis Child. 2008;93:428-32.

41. Houts PSD, Doak CC, Doak LG, Loscalzo MJ. The role of pictures in improving health communication: a review of research on attention, comprehension, recall and adherence. Patient Educ Couns. 2006;61:173-90.

42. Demir F, Ozsaker E, Ilce AO. The quality and suitability of written educational materials for patients. J Clin Nurs. 2008:17(2):259-65.

43. Williams MV, Davis T, Parker RM, Weiss BD. The role of health literacy in patient-physician communication. Family Med-Kans City. 2002;34(5):383-9.

44. Elwyn G, Todd S, Hibbs R, Thapar A, Edwards P, Webb A, et al. A 'real puzzle': the views of patients with epilepsy about the organisation of care. BMC Family Practice. 2003;4:4

45. WETHERBY AM, WATT N, MORGAN L, SHUMWAY S. Social communication profiles of children with autism Spectrum disorders late in the second year of life. J Autism Dev Disord. 2007;37:960-75

46. Kaiser AP, Hester PP, Mcduffie A. Supporting communication in young children with developmental disabilities. Ment Retard Dev Disabil Res Rev. 2007:7:143-50

47. Horowitz SH. Effective communication is the best medicine. Children's Voice. 2006;15:31-3.

48. Cegala DJ. Emerging trends and future directions in patient communication skills training. Health Commun. 2006:20:123-9.

49. Bradshaw J. Complexity of staff communication and reported level of understanding skills in adults with intellectual disability. J Intellect Disabi Res. 2001;45:233-43
50. Miles MB, Huberman AM. Qualitative data analysis: An expanded sourcebook. sage;1994.

51. Graneheim UH, Lundman B. Qualitative content analysis in nursing research: concepts, procedures and measures to achieve trustworthiness. Nurse Educ Today. 2004;24(2):105-12.

52. Creswell JW. Educational research: planning, conducting, and evaluating quantitative. Prentice Hall: Upper Saddle River; 2002.

53. KENDALL S, THOMPSON D, COULDRIDGE L. The information needs of carers of adults diagnosed with epilepsy. Seizure. 2004;13:499-508.

54. SIGN. Diagnosis and management of epilepsies in children and young people. A national clinical guideline. Anonymous, editor. Department of health: Edinburgh; 2005.

55. Scottish Paliament. Mental Health (Care and Treatemnt) (Scotland) Act. Edinburgh: Statioery Office; 2003.

56. Coulter A. What do patients and the public want from primary care? $\mathrm{Br}$ Med J. 2005;331(7526):1199-201.

57. Keller VF, Carroll JG. A new model for physician-patient communication. Patient Educ Couns. 1994:23:131-40.

58. Wrench JS, Booth-Butterfiled M. Increasing patient satisfaction and compliance: an examination of the physician humour orientation, compliance-gaining strategies, perceived credibility. Commun Q. 2003;51(4): 482-503.

59. Shore DA. Communicating in times of uncertainty: the need for trust. J Health Commun. 2003:8(S1):13-4.

60. Laine C, Davidoff F. Patient-centered medicine: a professional evolution. JAMA. 1996:275(2):152-6.

61. Daniel KS. Truth-telling in the doctor-patient relationship: a case analysis. Clinical Ethics, 2006:1(3):130-4

62. Sulman R, Singer M, Goldstone J, Bellingan G. Medication errors: a prospective cohort study of hand-written and computerised physician order entry in the intensive care unit. Crit Care. 2005;9(5):16-521.

63. Brabcová I, Bártlová S, Tóthová V, Prokešová R. The possibility of patient involvement in prevention of medication error. Kontakt. 2014:16(2):e65-70.

64. Lesar TS. Tenfold medication dose prescribing errors. Ann Pharmacother. 2002:36:1833-9.

65. Bobb A, Gleason K, Husch M, Feinglass J, Yarnold PR, Noskin GA. The epidemiology of prescibing errors. The potentials of computerized prescriber order entry. Arch Intern Med. 2004;164:785-92.

66. Whitehair $\mathrm{L}$, Provost $\mathrm{S}$, Hurley J. Identification of prescribing errors by preregistration student nurses: a cross-sectional observational study utilising a prescription medication quiz. Nurse Educ Today. 2014;34(2):225-32.

67. Gabay G. Perceived control over health, communication and patientphysician trust. Patient Educ Couns.

68. Ledford CJW, Villagran MM, Kreps GL, Zhao X, McHorney C, Weathers M, et al. "Practicing medicine": patient perceptions of physician communication and the process of prescription. Patient Educ Couns. 2010;80(3):384-92.

69. Tiffin PA, Perini AF. The use of antiepileptic drugs in learning disabled people with epilepsy: an audit of adult in-patients in a treatment and continuing care service. Seizure. 2001;10(7 (Print)):500-4.

70. Alvarez N, Besag F, livanainen M. Use of antiepileptic drugs in the treatment of epilepsy in people with intellectual disability. J Intellect Disabil Res. 1998; 42(Suppl 1):1-15.

71. Beavis J, Kerr M, Marson A. Non-pharmacological interventions for epilepsy in people with intellectual disabilities. Cochrane Database Syst Rev. 2007;4: $1-16$.

72. Street RL Jr, O'Malley KJ, Cooper LA, Haidet P. Understanding concordance in patient-physician relationships: personal and ethnic dimensions of shared identity. Ann Fam Med. 2008;6(3):198-205.

73. Weng HC, Chen HC, Chen HJ, Lu K, Hung SY. Doctors' emotional intelligence and the patient-doctor relationship. Med Educ. 2008;42(7):703-11.

74. Fiscella K, Meldrum S, Franks P, Shields CG, Duberstein P, McDaniel SH, et al. Patient trust: is it related to patient-centered behavior of primary care physicians? Med Care. 2004;42(11):1049-55.

75. Safran DG, Taira DA, Rogers WH, Kosinski M, Ware JE, Tarlov AR. Linking primary care performance to outcomes of care. J Fam Pract. 1998:47:213-20.

76. Gerteis M, Edgman-Levitan S, Daley J, Delbanco TL. Through the Patient's eyes: understanding and promoting patient-centered care. J Healthc Qual. 1997:19(3):43.

77. Shaller D. Patient-centred care: what does it takes. Oxford: Picker Institute; 2007.

78. van der Gaag A. Communication skills and adults with learning disabilities: eliminating the professional myopia. Br J Learn Disabil. 1998;26:88-93. 